\title{
Assessment of the therapeutic potential of anti-miR 24 and anti-miR 34 in cardiac diseases
}

\author{
Chunli Li, Jue Li, Xiaojun Sun*, Jin Huang, Chunyan Yao \\ Department of Cardiovascular Medicine, Wenshan People's Hospital, 228 Kaihua Middle Road, Wenshan City, Yunnan \\ Province 663000, China
}

*For correspondence: Email: JoyTrevinoqcu@yahoo.com; Tel/Fax: 0086-0876-2127918

\begin{abstract}
Purpose: To study the therapeutic effects of anti-miR-24 and anti-miR-34 in cardiac diseases Methods: H9c2 rat cardiomyocyte cell lines were transfected with the synthetic oligonucleotides antimiR-24 and anti-miR-34 which reduced the expressions of miR-24 and miR-34. Proliferation assay, real time-polymerase chain reaction (RT-PCR) and immunoblotting were carried out to determine the effect of the transfections on cardiomyocyte proliferation, expressions of miR-24 and miR-34, as well as expressions of the target genes, TGF- $\beta 1$ and E2F3.

Results: The proliferation ability of the transfected cells was decreased significantly, relative to negative control. In contrast, percentage apoptosis was higher in the negative control group than in transfected cells. The expression profiles of anti-miR-24 and anti-miR-34 were significantly reduced, when compared to negative control. These results were further confirmed using immunoblot which revealed that the expression of the target genes, TGF- $\beta 1$ and E2F3, were upregulated in the transfected cells. Conclusion: These results suggest that the synthetic oligonucleotides (anti-miR-24 and anti-miR-34) might be useful in developing therapeutic drug targets for cardiac diseases by suppressing the expressions of miR-24 and miR-34.
\end{abstract}

Keywords: H9c2rat cardiomyocyte miRNA, Anti-miR-24, Anti-miR-34, Cardiac diseases

\begin{abstract}
This is an Open Access article that uses a fund-ing model which does not charge readers or their institutions for access and distributed under the terms of the Creative Commons Attribution License (http://creativecommons.org/licenses/by/4.0) and the Budapest Open Access Initiative (http://www.budapestopenaccessinitiative.org/read), which permit unrestricted use, distribution, and reproduction in any medium, provided the original work is properly credited.
\end{abstract}

Tropical Journal of Pharmaceutical Research is indexed by Science Citation Index (SciSearch), Scopus, International Pharmaceutical Abstract, Chemical Abstracts, Embase, Index Copernicus, EBSCO, African Index Medicus, JournalSeek, Journal Citation Reports/Science Edition, Directory of Open Access Journals (DOAJ), African Journal Online, Bioline International, Open-J-Gate and Pharmacy Abstracts

\section{INTRODUCTION}

Myocardial infarction (MI) is one of the most frequently occurring cardiovascular diseases worldwide, and it is associated with high morbidity and mortality [1]. The disease is characterized by myocardial necrosis due to severe hypoxia-ischemia of coronary arteries which lead to heart failure [2]. It has been predicted that between 2020 and 2030, approximately 16-23 million people will be affected by MI [3]. Therefore, there is need for fast and accurate diagnostic procedures for $\mathrm{MI}$ so as to arrest the severity of the disease and save patients' lives.

Currently, there exists a miscellaneous array of biochemical markers for diagnosis of MI. These are creatine kinase, cardiac troponin I, brain natriuretic peptide, creatine kinase $\mathrm{MB}$ isoform, and lactate dehydrogenase [4]. However, due to low specificity and sensitivity, these biomarkers 
sometimes give rise to false positive diagnosis [5]. MicroRNAs (miRNAs) are the most promising and potential biomarkers with high sensitivity and selectivity for the early diagnosis of cardiovascular diseases. MicroRNAs are small, non-coding RNAs, each with approximately 1826 nucleotides in length. These miRNAs anneal with the corresponding nucleotides in the target mRNAs, thereby repressing the synthesis of disease associated proteins [6].

Apart from being found in tissues, miRNAs are also present in certain body fluids such as plasma, urine and serum [7]. Abnormally expressed miRNAs were seen in patients suffering from acute myocardial infarction, coronary artery disease, acute coronary syndrome, hypertension, and stroke. Several studies have shown the involvement of miRNA in many cardiovascular diseases. Studies have also revealed that in acute myocardial infarction, miR208 [8], miR-499 [9] and miR-1 [10] were aberrantly elevated. It has been shown that collagen synthesis was inhibited by miR-29, leading subsequently to myocardial infarction [11]. It has been reported that $\mathrm{miR}-34$ a regulated fibrosis after myocardial infarction by targeting the gene Smad4, while elevated expression of miR-24 impaired the function of smooth muscle cells [12]. From these studies, it is clear that miRNAs may be key regulators in cardiovascular diseases. Therefore, it is crucial to seek modern therapeutic interventions for decreasing the expression of miRNAs so as reduce the prevalence of cardiovascular diseases. Recently, antisense therapies using anti-miRNAs were shown to target diseases related to miRNAs in vivo. These anti-miRNAs reduced the pathogenicity and abnormal expressions of miRNAs by regulating the translation of mRNAs which are normally targeted by the miRNAs [13].

The present study investigated the therapeutic potential of anti-miR-24 and anti-miR-34 in myocardial infarction, using $\mathrm{H} 9 \mathrm{c} 2$ rat cardiomyocyte cell line.

\section{EXPERIMENTAL}

\section{Cell culture and transfection}

The $\mathrm{H} 9 \mathrm{c} 2$ rat cardiomyocyte cell line was cultured in Dulbecco's Modified Eagle Medium (DMEM) containing $10 \%$ fetal bovine serum in a humidified incubator containing $5 \% \mathrm{CO}_{2}$ at $37^{\circ} \mathrm{C}$. Transfection was carried out using standard protocols [14]. Cells were seeded into 6-well plate at a density of $1 \times 10^{5}$ cells/well, and transfection was performed after $24 \mathrm{~h}$. Using standard protocols, the cells were transfected with anti-miR-24, anti-miR-34, miR-24 and miR34 using Lipofectamine 2000 (Invitrogen, USA). The culture medium was replaced after $4 \mathrm{~h}$, and the experiments were carried out in triplicate. The transfected cells were grouped into the following categories: non-transfected cells (control), cells transfected with miRNAs (miR-24 and miR-34 i.e. negative control), and cells transfected with anti-miRNAs (anti-miR-24 and anti-miR-34).

\section{Cell proliferation assay}

The proliferation of transfected cells was determined using CCK-8 assay. Cells from each group were seeded in 96-well plates at a density of $5 \times 10^{4}$ cells $/ \mathrm{ml}$, and incubated for $24 \mathrm{~h}$. Then, to each well, $10 \mu \mathrm{L}$ of CCK-8 solution was added and the cells were again incubated for $2 \mathrm{~h}$ at $37^{\circ} \mathrm{C}$. The optical density was read at $450 \mathrm{~nm}$ in a microplate reader (Bio-Rad, USA).

\section{Determination of cell apoptosis}

Transfected cells at logarithmic growth phase were seeded in 6-well plate at a density of $1 \times 10^{5}$ cells $/ \mathrm{mL}$, and incubated for $24 \mathrm{~h}$. The cells were then stained using Annexin V-FITC (Invitrogen, USA) for $15 \mathrm{~min}$, and further subjected to flow cytometric analysis.

\section{Identification of miR-24 and miR-34 targets}

The target genes of miR-24 and miR-34 were predicted with Bioinformatics using the databases TargetScan (www.targetscan.org), miRTarBase

(www.mirtarbase.mbc.nctu.edu.tw/php) and miRDB (www.mirdb.org).

\section{Isolation of RNA from transfected cells}

Total RNA was isolated from transfected $\mathrm{H} 9 \mathrm{c} 2$ rat cardiomyocytes using TRIzol reagent as per standard protocol. The purity and concentration of RNA were determined with NanoDrop, while RNA integrity was ascertained with agarose gel electrophoresis. The RNA was then kept frozen at $-80^{\circ} \mathrm{C}$ prior to further analysis.

\section{Quantitative RT-PCR analysis}

Quantitative RT-PCR was performed using mirVanaq RT-PCR miRNA Detection Kit (P/N: 1556, Ambion). The RT-PCR for transfected cells and target genes was carried out using standard procedure [15]. Samples of RNA were reversetranscribed to cDNA by incubating the vials at $37^{\circ} \mathrm{C}$ for $30 \mathrm{~min}$. The $\mathrm{PCR}$ reaction system comprised $4.5 \mu \mathrm{L} 2 \times$ SYBR Green Mixture, 
Table 1: Primer sequences used in this study

\begin{tabular}{lll}
\hline Gene & Forward primer (5'-3') & Reverse primer (5'-3') \\
\hline Anti-miR-24 & CACACTATATCACATTGCCAG & ATGGTTGTTCTGCTCTCTGTCC \\
Anti-miR-34 & GTAACAGCAACTCCATGTG & CTGTCAACGATACGCTAC \\
miR-24 & TCACACTATATCACATTGCCAGG & TATGGTTGTTCTGCTCTCTGTCTC \\
miR-34 & TGTAACAGCAACTCCATGTGG & GCTGTCAACGATACGCTACG \\
U6 & ATTGGAACGATACAGAGAAGAT & GGAACGCTTCACGAATTTG \\
$\beta$-actin & AACAGTCCGCCTAGAAGCAC & CGTTGACATCCGTAAAGA \\
\hline
\end{tabular}

forward and reverse primers $(0.5 \mu \mathrm{L}$ each, $5 \mu \mathrm{M})$; $1 \mu \mathrm{L}$ of cDNA, and $3.5 \mu \mathrm{L}$ of $\mathrm{ddH}_{2} \mathrm{O}$. The reaction was performed on $\mathrm{ABI} \mathrm{ViiA} 7$ at $95^{\circ} \mathrm{C}$ for $5 \mathrm{~min}$, followed by 40 cycles of $95^{\circ} \mathrm{C}$ for $15 \mathrm{sec}$ and $60^{\circ} \mathrm{C}$ for $60 \mathrm{sec}$. The expressions in transfected cells were analyzed using $\mathrm{Ct}$ method i.e.2- $\Delta \triangle \mathrm{CT}$, where $\triangle \triangle C T=[C T$ (anti-24/anti-34/miR-24/miR34) - CT(5S rRNA)] [16]. The experiments were repeated thrice to obtain accurate data, with U6 and $\beta$-actin as control. The primers used for qRT-PCR are shown in Table 1.

\section{Immunoblot analysis of TGF- $\beta 1$ and E2F3q}

Protein samples were isolated using mirVanaPariS isolation kit according to the manufacturer's protocol, and protein concentration was measured using Lowry's assay. Equal amounts of protein samples were resolved using $12 \%$ SDS-polyacrylamide gel electrophoresis and transferred to polyvinylidene membrane. The membrane was treated with $5 \%$ BSA (Sigma-Aldrich; Cat. No. 05470) to block non-specific binding of the blot. Thereafter, the membrane was incubated with primary antibodies, i.e., anti-TGF- $\beta 1$ (Cat. No. MAB4310) and anti-E2F3 (Cat. No. P0056) overnight, followed by incubation with horse radish peroxide-conjugated secondary antibody at room temperature. The signals were detected and recorded using enhanced chemiluminescence detection system. $\beta$-actin was used as a loading control.

\section{Statistical analysis}

Statistical analysis was done using SPSS for Windows 11.0 (SPSS, Inc, Chicago, IL, USA). Measurement data are expressed as mean \pm standard deviation. All the experiments were carried out in triplicate. Values of $p<0.05$ were taken as indicative of statistical significance.

\section{RESULTS}

Effect of transfection on proliferation and apoptosis of $\mathrm{H} 9 \mathrm{c} 2$ rat cardiomyocytes

The proliferative ability of $\mathrm{H} 9 \mathrm{c} 2$ cardiomyocytes transfected with anti-mir-24 and anti-miR-34 was significantly decreased, when compared with that of the negative control group (Figure 1A). Moreover, percentage cell apoptosis was markedly decreased in the anti-miR-24 and antimiR-34 transfected cells. In contrast, percentage apoptosis was high in cells transfected with miR24 and miR-34 (Figure 1B).
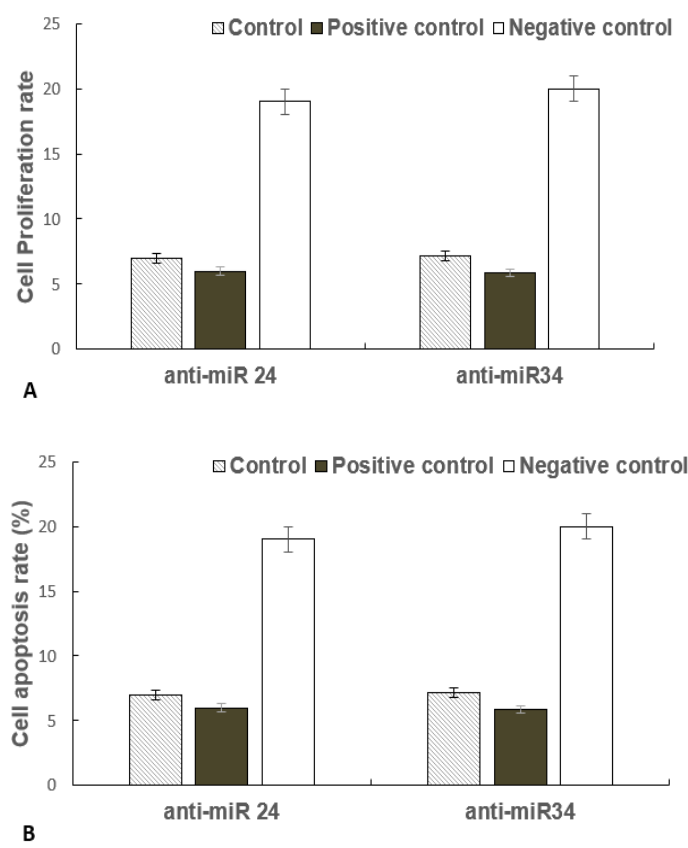

Figure 1: Cell proliferation and apoptosis of $\mathrm{H} 9 \mathrm{c} 2$ cardiomyocytes. A. Proliferation of $\mathrm{H} 9 \mathrm{c} 2$ cardiomyocytes transfected with anti-miR-24 and antimiR-34. B. Apoptosis of H9c2 cardiomyocytes transfected with anti-miR-24 and anti-miR-34

\section{Expression patterns of anti-miRNAs in transfected cells}

Quantitative qRT-PCR showed that the expression profiles of anti-miR-24 and anti-miR34 were markedly downregulated, relative to the negative control group. This finding indicates that anti-miRNAs can be used as a therapeutic strategy in myocardial infarction. These results are shown in Figure 2.

\section{Protein expression levels of TGF- $\beta 1$ and E2F3 in anti-miRNA transfected cells}

In order to confirm the regulation of the target 


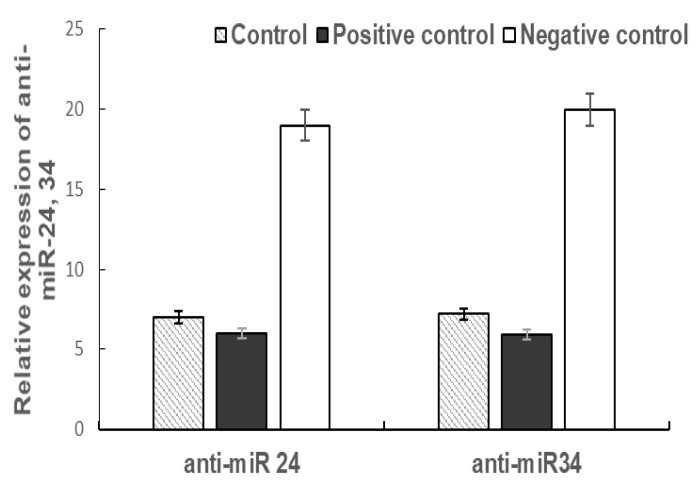

Figure 2: Relative expression patterns of anti-miR-24 and anti-miR-34 in $\mathrm{H} 9 \mathrm{c} 2$ rat cardiomyocyte transfected cells

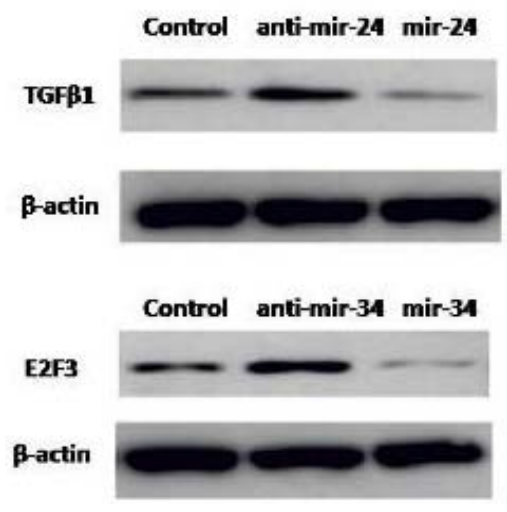

Figure 3: Analysis of protein expression patterns of TGF- $\beta 1$ and E2F3 in transfected $\mathrm{H} 9 \mathrm{c} 2$ rat cardiomyocyte cells. Beta actin was used as control

genes, immunoblotting was carried out. The expressions of the genes TGF- $\beta 1$ and E2F3 were significantly increased in the anti-miR-24 and anti-miR-34 transfected cells, when compared with the negative control (Figure 3 ). This result indicated clearly that anti-miRNA repressed miRNAs. Thus, the mRNAs of the target genes involved in translation process were not inhibited, resulting in upregulation of their expressions.

\section{DISCUSSION}

Myocardial infarction, a cardiovascular disease, causes heart failure in humans [17]. Several studies have shown that aberrant expression of miRNAs is involved in the pathogenesis of many diseases. It has been revealed that, apart from being present in tissues, miRNAs are found in the blood and urine, making them prominent biomarkers for numerous ailments, including cardiovascular diseases $[7,18,19]$. Therefore, it is necessary to evolve alternate ways for downregulating miRNAs so as to reduce the progression of cardiovascular diseases.
Recently, anti-miRNAs were found to be efficient in the development of remedies for many diseases.

In this study, $\mathrm{H} 9 \mathrm{c} 2$ rat cardiomyocyte cell line was used for determination of the therapeutic potential of anti-miR-24 and anti-miR-34 in cardiovascular disease. The results showed that cells transfected with anti-miRNAs showed decreased proliferation rate, and in addition, apoptosis was also reduced, relative to the negative control. The expression profiles of antimiR-24 and anti-miR-34 were reduced significantly, when compared with the negative control group. The target gene of anti-miR-24 was found to be TGF- $\beta 1$, while the target gene for anti-miR-34 was E2F3. The expressions of the target genes were upregulated in cells transfected with anti-miR-24 and anti-miR-34, when compared to the negative control.

Based on these results, it is obvious that the knockdown of anti-miR-24 and anti-miR-34 reduced the expressions of miR-24 and miR-34. As a result, degradation of mRNA was prevented and translation was initiated, which in turn, upregulated the expressions of the target genes TGF- $\beta 1$ and E2F3, thereby preventing the progression of the disease. These findings correlate with recent reports which showed that subcutaneous delivery of anti-miR-208a in rats not only silenced the miR-208a in heart tissue, but also prevented pathological changes such as myosin switching and cardiac remodeling, leading to increased survival of the rats [20].

Moreover, administration of exogenous anti-miR590 and anti-miR-199a promoted cardiac repair in neonatal and adult myocardial-infarcted mice [21]. Administration of anti-miR-210 in myocardial infarcted murine model reduced apoptosis and improved heart function by targeting Efna3 and Ptp1b [22]. Moreover, expression of miR-34a and anti-miR-92a promoted potential therapeutic effects on acute myocardial infarction [23,24].

The present study has revealed the therapeutic potential of anti-miR-24 and anti-miR-34. This might be beneficial for evaluating the therapeutic dose, and for forecasting therapeutic outcome in individuals affected by cardiovascular diseases. Although the precise mechanism underlying the regulation of the target genes under disease situations is not yet clear, this study provides some benefits related to the potential use of antimiRNAs as new therapeutic tools. The pharmacological properties of anti-miRNAs can adjust based on the mode and outcome of the disease. This might be helpful in assessing the effect and therapeutic dose in affected 
individuals. The effectiveness of anti-miRNAs in regulating gene expression will be determined through identification of the mechanism involved. This will be helpful for developing novel therapeutics.

\section{CONCLUSION}

Synthetic oligonucleotides, anti-miR-24 and antimiR-34 are crucial in the development of target drugs for treating cardiac diseases. Based on the results obtained in this study, it may be reasonably concluded that synthetic oligonucleotides (anti-miR-24 and anti-miR-34) might be used for developing therapeutic drug targets for suppressing the expressions of miR24 and miR-34, thereby reducing the incidence of cardiac diseases.

\section{DECLARATIONS}

\section{Acknowledgement}

The authors thank the Institution, Institutional Review Board and Ethics Committee for providing funds and support to carry out the research.

\section{Conflict of interest}

The authors declare that no conflict of interest is associated with this research.

\section{Contribution of authors}

We declare that this work was done by the authors named in this article and all liabilities pertaining to claims relating to the content of this article will be borne by the authors. Chunli Li, Jue $\mathrm{Li}$ contributed to this work equally. The research work was designed by the corresponding author Dr. Xiaojun Sun and Jin Huang. In addition, the manuscript was written by Dr. Xiaojun Sun and Jin Huang. The research work was done equally by Dr. Chunli Li and Dr.Jue Li. RT-PCR and Western blotting experiments was carried out by Dr. Jin Huang and Dr. Chunyan Yao, respectively.

\section{Open Access}

This is an Open Access article that uses a funding model which does not charge readers or their institutions for access and distributed under the terms of the Creative Commons Attribution License (http://creativecommons.org/licenses/by/ 4.0) and the Budapest Open Access Initiative (http://www.budapestopenaccessinitiative.org/rea d), which permit unrestricted use, distribution, and reproduction in any medium, provided the original work is properly credited.

\section{REFERENCES}

1. White $H D$, Chew DP. Acute myocardial infarction. Lancet 2008; 372: 570-584.

2. Lisowska A, Makarewicz-wujec M, Fi Lipiak KJ. Risk factors, prognosis and secondary prevention of myocardial infarction in young adults in Poland. Kardiol Pol 2016; 74: 1148-1153.

3. Moran A, Gu D, Zhao D, Coxson P, Wang YC, Chen CS, Liu J, Cheng J, Bibbins-DoMinGo K, Shen YM, et al. Future cardiovascular disease in china: markov model and risk factor scenario projections from the coronary heart disease policy model-China. Circ Cardio vasc Qual Outcomes 2010; 3: 243-252.

4. De LeMos JA, DraZner MH, Omland T, Ayers CR, Khera A, Rohatgi A, Hashim I, Berry JD, Das SR, Morrow DA, Mc Guire D. Association of troponin $T$ detected with a highly sensitive assay and cardiac structure and mortality risk in the general population. JAMA 2010; 304: 2503-2512.

5. Moore E, Bellomo R, Nichol A. Biomarkers of acute kidney injury in anesthesia, intensive care and major surgery: From the bench to clinical research to clinical practice. Minerva Anestesiol 2010; 76: 425-440.

6. Bartel DP. MicroRNAs: target recognition and regulatory functions. Cell 2009; 136: 215-233.

7. Chim SS, Shing TK, Hung EC, Leung TY, Lau TK, Chiu $R W$, Dennis Lo Y. Detection and characterization of placental microRNAs in maternal plasma. Clin Chem 2008; 54: 482-490.

8. Ji X, Takahashi R, Hiura Y, Hirokawa G, Fukushima Y, Iwai N. Plasma miR-208 as a biomarker of myocardial injury. Clin Chem 2009; 55: 1944-1949.

9. Olivieri $F$, Antonicelli $R$, Lorenzi $M$, D'Alessandra $Y$, Lazzarini $R$, Santini G, Spazzafumo L, Lisa $R$, La Sala $L$, Galeazzi R. Diagnostic potential of circulating miR499-5p in elderly patients with acute non ST-elevation myocardial infarction. Int J Cardiol 2013; 167: 531-536.

10. Cheng Y, Tan N, Yang J, Liu X, Cao X, He P, Dong X, Qin S, Zhang C. A translational study of circulating cellfree microRNA-1 in acute myocardial infarction. Clin Sci (Lond) 2010; 119: 87-95.

11. Van Rooij E, Sutherland LB, Thatcher JE, Di Maio JM, Naseem RH, Marshall WS, Hill JA, Olson EN. Dysregulation of microRNAs after myocardial infarction reveals a role of miR-29 in cardiac fibrosis. Proc Natl Acad Sci USA 2008; 105: 13027-13032.

12. Huang Y, Qi Y, Du JQ, Zhang DF. MicroRNA-34a regulates cardiac fibrosis after myocardial infarction by targeting Smad4. Expert Opin Ther Targets 2014; 18: 1355-1365.

13. Van Rooij E, Olson EN. Micro RNA therapeutics for cardiovascular disease: opportunities and obstacles. Nat Rev Drug Discov 2012; 11: 860-872.

Trop J Pharm Res, July 2020; 19(7): 1439 
14. Ji R, Cheng Y, Yue J, Yang J, Liu X, Chen H, Dean DB, Zhang C. MicroRNA expression signature and antisense-mediated depletion reveal an essential role of microRNA in vascular neointimal lesion formation. Circ Res 2007; 100: 1579-1588.

15. Chen C, Ridzon DA, Broomer AJ, Zhou Z, Lee DH, Nguyen JT, Barbisin M, Xu NL, Mahuvakar VR, Andersen MR. Real-time quantification of microRNAs by stem-loop RT-PCR. Nucleic acids Res 2005; 33: e179.

16. Schmittgen TD, Jiang J, Liu Q, Yang L. A high-throughput method to monitor the expression of microRNA precursors. Nucleic acids Res 2004; 32: e43-e43.

17. Lim S, Koh YS, Kim PJ, Kim HY, Park CS, Lee JM, Kim $D B$, Yoo KD, Jeon DS, Her $S H$ et al. Incidence, implications, and predictors of stent thrombosis in acute myocardial infarction. Am J Cardiol 2016; 117: 15621568.

18. Chen X, Ba Y, Ma L, Cai X, Yin Y, Wang K, Guo J, Zhang $Y$, Chen J, Guo X. Characterization of microRNAs in serum: a novel class of biomarkers for diagnosis of cancer and other diseases. Cell Res 2008; 18: 9971006.

19. Gilad S, Meiri E, Yogev Y, Benjamin S, Lebanony D, Yerushalmi $N$, Kushnir $M$, Cholakh $H$, Melamed $N$,
Bentwich Z, Hod M. Serum microRNAs are promising novel biomarkers. PLoS ONE 2008; 3: e3148.

20. Montgomery RL, Hullinger TG, Semus HM, Dickinson $B A$, Seto AG, Lynch JM, Stack C, Latimer PA, Olson EN, Van Rooij E. Therapeutic inhibition of miR-208a improves cardiac function and survival during heart failure. Circulation 2011; 124: 1537-1547.

21. Eulalio A, Mano M, Dal Ferro M, Zentilin L, Sinagra G, Zacchigna S, Giacca M. Functional screening identifies miRNAs inducing cardiac regeneration. Nature 2012; 492: 376-381.

22. Hu S, Huang M, Li Z, Jia F, Ghosh Z, Lijkwan MA, Fasanaro P, Sun N, Wang X, Martelli F. MicroRNA-210 as a novel therapy for treatment of ischemic heart disease. Circulation 2010; 122: S124-131.

23. Boon RA, lekushi $K$, Lechner $S$, Seeger $T$, Fischer $A$, Heydt S, Kaluza D, Tréguer K, Carmona G, Bonauer A. MicroRNA-34a regulates cardiac ageing and function. Nature 2013; 495: 107-110.

24. Bonauer A, Carmona G, Iwasaki M, Mione M, Koyanagi $M$, Fischer A, Burchfield J, Fox H, Doebele C, Ohtani K. MicroRNA-92a controls angiogenesis and functional recovery of ischemic tissues in mice. Science 2009; 324: $1710-1713$. 